\title{
La investigación genealógica en los archivos eclesiásticos: fuentes y metodología
}

Genealogical research in ecclesiastical archives: sources and methodology

\author{
María Guadalupe PÉRez Ortiz (1), Francisco GonzÁlez LozAno (1), Agustín Vivas (2)
}

(1) Seminario Metropolitano de San Atón de Badajoz, España,mgperort@gmail.com,fglozano@hotmail.com (2) Universidad de Extremadura aguvivas@unex.es

\begin{abstract}
Resumen
La genealogía ha adquirido en las últimas décadas un despertar inusitado, modificando de forma decisiva algunos de los procesos que se realizan en nuestros archivos. Los archivos de la Iglesia contienen una enorme cantidad de datos de sustancial importancia para el trazado de genealogías. Sin embargo, esta riqueza de contenidos es en muchos casos inversamente proporcional a los medios técnicos y humanos (formación, tiempo, etc.) tanto de los archiveros eclesiásticos como de los usuarios. Para la consecución de un buen estudio genealógico es imprescindible utilizar un método que guíe la recolección de información, representación y análisis. A lo largo de este estudio se ofrecen pautas metodológicas que puedan conducir hacia una nueva praxis archivísticoeclesiástica en contenidos genealógicos que vaya más allá de los registros parroquiales, considerados por muchos como la única fuente archivísticoeclesiástica que los contiene.
\end{abstract}

Palabras clave: Genealogías. Archivos eclesiásticos. Metodología. Método genealógico. Fuentes documentales. Investigación histórica. Investigación genealógica. Iglesia Católica. España.

\section{Introducción}

La genealogía ha adquirido en los últimos años un despertar muy importante, en cuanto a su carácter de ciencia auxiliar de la historia, la demografía, la economía, la sociología, etc. Los estudios genealógicos coadyuvan a interpretar el origen, desarrollo y evolución de los pobladores de un territorio, constituyendo una herramienta indispensable para la historiografía y las ciencias sociales.

Pretendemos poner en relieve a los archivos de la Iglesia como generadores, gestores y conservadores de los principales contenidos genealógicos que se custodian en archivos de nuestro país. En España, las fuentes esenciales para la investigación genealógica son dos: los archivos civiles y los eclesiásticos. De estos últimos los más relevantes son los registros parroquiales; aunque en esta investigación presentaremos otras tipologías archivístico-eclesiásticas que

\begin{abstract}
Genealogy has acquired in the last decades an unusual awakening, modifying some of the processes that are carried out in our archives. The Church archives contain an enormous amount of data of substantial importance for the tracing of genealogies. However, this source of content is in many cases inversely proportional to the available technical and human resources (expertise, time, etc.) of both ecclesiastical archivists and users. We are aware that, in order to obtain a good genealogical study, it is essential to use a proper method for collecting, representing and analysing genealogical information. In this article we try to offer methodological guidelines that will lead us to a new archival-ecclesiastical praxis with genealogical contents that goes beyond parochial registers, considered by many as the only archivalecclesiastical source that conveys them.
\end{abstract}

Keywords: Genealogies. Ecclesiastical archives. Methodology. Genealogical method. Information sources. Historical research. Genealogical research. Catholic Church. Spain.

contienen datos sustanciales para el trazado de genealogías, cuando el acceso a los archivos parroquiales es restringido, el documento no se conserva o el archivo no está a nuestro alcance. La anotación sistemática de nacimientos, bautizos, matrimonios y defunciones nos permitirá encadenar las generaciones y dar adecuada forma al armazón genealógico que posteriormente deberemos ir complementando con otros datos a los que podremos acceder consultando diversas fuentes de reconocido prestigio en cuestiones genealógicas en España como las de Berdún Nadal, 2008; Cadenas, 1975, 1978; Fluvià i Escorsa, 1995 y Salazar, 2006 y recursos en Internet como los de la Asociación de Genealogía Española, los Cuadernos de Genealogía, el Directorio de Genealogía, la Guía Genealógica y el Manual de Genealogía.

Somos conscientes, y por ello esta contribución, que abordar estos aspectos es una cuestión absolutamente necesaria en el siglo XXI, cuan- 
do podemos afirmar que estamos ante un boom genealógico. Nuestros archivos, los archivos eclesiásticos, día a día, se ven repletos de usuarios que intentan localizar datos que les permitan trazar historias, ya sea para investigaciones exhaustivas que dan lugar a estudios y publicaciones sobre temas genealógicos, ya sea para la localización de sus antepasados. Ante ello, el archivero eclesiástico debe estar preparado. Asimismo, consideramos que la formación de nuestros usuarios es también una cuestión primordial que incluye, claro está, la enseñanza y la investigación, pues estos aspectos son ineludibles para alcanzar unos satisfactorios resultados.

Este trabajo parte del análisis de los archivos eclesiásticos, mejor dicho, de las realidades que en ellos se desarrollan en relación al tema que nos compete. En nuestra investigación se han detectado dos problemas: en primer lugar, nuestros usuarios desconocen más allá de los registros parroquiales, qué otros archivos eclesiásticos pueden proporcionales datos de carácter genealógico; y en segundo término, dónde y cómo localizar los contenidos genealógicos dentro de los cuadros de clasificación de los diferentes archivos eclesiásticos. Para llegar a estas conclusiones, previamente se ha efectuado un análisis de casos cuyas aportaciones son las que nos permiten plantear la problemática que se está desarrollando en los archivos de la Iglesia en relación a cuestiones genealógicas. Las fuentes documentales son escasas, limitándose a trabajos a nivel teórico; por lo general, investigaciones empíricas sobre la praxis archivística en gestión de la documentación con contenidos genealógicos. Siguiendo una metodología más práctica que teórica, aunque basada en principios archivísticos, históricos y genealógicos, nos proponemos proporcionar a los usuarios conocimientos y técnicas que les permitan alcanzar los objetivos de sus investigaciones, es decir, desarrollar una praxis archivístico-eclesiástica en materia genealógica, donde la base son los documentos de archivo, ya que son el testimonio vivo de nuestro pasado y un legado permanente hacia nuestro futuro.

En base a ello, los objetivos que nos proponemos son cuatro: ofrecer a los usuarios herramientas y pautas de actuación sencillas para la localización de contenidos genealógicos en los archivos de la Iglesia; dar a conocer el método genealógico como base en este tipo de investigaciones; exponer dentro del marco de archivos eclesiásticos aquellos centros que contienen datos genealógicos para que los trabajos de nuestros usuarios no se limiten exclusivamente a los registros parroquiales; y presentar las sec- ciones y series documentales dentro de los cuadros de clasificación de los archivos eclesiásticos que contienen estos contenidos.

Para ello, nuestra contribución se encuentra estructurada de la siguiente forma: en una sección inicial desarrollamos una breve aproximación a las fuentes de información en materias genealógicas, haciendo hincapié en las de tipo eclesiástico. A continuación, ofrecemos unas pautas metodológicas en las que intentamos poner de manifiesto la importancia de la utilización de un método en los trabajos relacionados con genealogías. Más tarde, nos centraremos en los archivos eclesiásticos que contienen contenidos genealógicos para ofrecer las principales secciones y series que albergan este tipo de información. Por último, ofreceremos unas conclusiones generales.

\section{Aproximación a las fuentes de información}

En la antigüedad la tradición oral era fundamental en cuestiones de carácter genealógico pero el devenir de los tiempos nos sitúa el documento de archivo como la primera y principal fuente de datos fiables para el trazado de genealogías. Una de las reglas básicas de la genealogía consiste en no dar por cierto nada hasta que no ha sido constatado por medio de un documento. Para la construcción de un perfil genealógico se necesitan datos que proporcionen la suficiente información sobre nuestros parientes o sujetos de interés: nombres, apellidos, fechas, lugares, etc., relacionados con nuestra ascendencia. Estos son los datos que los usuarios deben localizar enlos archivos. Para ello, es muy útil y facilitaría enormemente la labor del archivero que el usuario formado previamente supiera dónde y cómo localizar los contenidos, es decir, que pueda utilizar las herramientas con las que contamos en nuestros centros (inventarios, guías, cuadros de clasificación, etc.).

En líneas generales, dado que no es la base fundamental de esta investigación, para la localización de contenidos de carácter genealógico los usuarios pueden acceder a diversas fuentes archivísticas: los archivos particulares, los civiles y los eclesiásticos.

Respecto a los archivos particulares (Belmonte García, 2011; Bravo Lledó, 2004; Espinosa Ramírez, 1995; Galiana Chacón, 2004; Gallego Domínguez, 1993; Segura Urra, 2014), numerosas personas conservan documentación referida a su familia, que puede resultar de suma utilidad. Incluso algunos han bosquejado árboles genealógicos que han servido de referencia para enriquecer ciertas investigaciones. En Es- 
paña la mayor parte de los archivos personales y familiares se hallan custodiados en instituciones públicas, entre las que destacan los archivos estatales (Belmonte García, 2011, p. 5). Podremos encontrar documentos tales como fotografías, cartas, diarios, invitaciones a bautizos, primeras comuniones, matrimonios, libros de familia, cartillas militares, libros de escolaridad, títulos de propiedad, carnés de pertenencia a asociaciones o instituciones, recortes de obituarios que contienen nombres, parentescos y detalles de la familia, etc.

En cuento a los archivos civiles en España, el primero se puso en marcha el 1 de enero de 1841 y fue sustituido por un nuevo sistema, todavía vigente, a partir del 1 de enero de 1871 (Alfaro de Prado, 2014). Creados a imagen y semejanza de los mantenidos por la Iglesia, los registros civiles establecen la anotación de nacimientos, matrimonios y defunciones independientemente de la condición religiosa del individuo.

Los documentos fundamentales del registro civil son: la partida de nacimiento, la de matrimonio y el certificado de defunción. En la partida de nacimiento constan el nombre y los apellidos del recién nacido, hora, día, mes y año, población, calle, número en donde se produjo el nacimiento o clínica -normalmente el domicilio de los padres-; nombres y apellidos, fecha, lugar de nacimiento, estado, edad y profesión de los padres; así como el lugar de nacimiento, estado y nombre de los abuelos paternos y maternos, y sus profesiones; y fecha en que se extendió el asiento, así como los testigos presentes en el acto de la inscripción y la firma de todos ellos. En la partida de matrimonio, están el nombre y apellidos de los contrayentes, con indicación de estado, domicilio y nacionalidad, fechas y lugares de sus nacimientos y nombres de sus padres, naturaleza de los mismos, fecha del acta y testigos. Finalmente en el certificado de defunción, el nombre y apellidos, estado, nacionalidad, profesión y fecha de nacimiento, nombre del padre y de la madre, hora, día, mes y año y lugar del fallecimiento, causa del mismo y cementerio en donde recibió sepultura el cadáver, nombre del padre y de la madre, del consorte e hijos, si los tuviere, así como la fecha de cuando se extendió el asiento, nombre del declarante y nombre del médico que extendió el certificado.

Respecto a los archivos eclesiásticos, son considerados como las fuentes más relevantes para el trazado de genealogías; para algunos autores son incluso "la única fuente demográfica disponible de carácter global y de una manera continuada..." (Fugueras y Mundet, 2004, p. 58). A partir de la celebración del Concilio de Trento en 1563, las parroquias quedan obligadas a reco- ger en libros los datos de sus feligreses, especialmente los relativos a nacimientos, matrimonios y defunciones (Diego, 2000, p. 341). Esta normativa será de aplicación obligatoria en España desde el 12 de julio de 1564, fecha en que el rey Felipe II decretó oficialmente la ejecución de lo acordado en el Concilio (García Pérez, 2009 , p. 3). En nuestra opinión, podemos situar aquí el verdadero nacimiento de la genealogía como ciencia auxiliar de la historia, si dejamos al margen la oralidad y nos basamos exclusivamente en documentos.

Sin embargo, y aunque los archivos parroquiales son la fuente fundamental de contenidos genealógicos desde el siglo XVI en España, no son los únicos que proporcionan este tipo de datos en el marco de los archivos de la Iglesia. Nuestros usuarios deben por tanto conocer otros archivos eclesiásticos portadores también de estos contenidos, máxime cuando algunos archivos parroquiales han desaparecido por diferentes vicisitudes a lo largo de los tiempos, llámense guerras, incendios, expolios, saqueos, etc., o se encuentran fuera de nuestro alcance para poder ser consultados. ¿Por qué decimos esto? Porque las conversaciones mantenidas con diferentes archiveros eclesiásticos, muy especialmente en el territorio extremeño en el que venimos trabajando debido a nuestro ámbito de estudio, pero extrapolables al territorio español, nos proporcionan datos reales en los que la gran mayoría de sus usuarios identifican únicamente el archivo parroquial como custodio de contenidos genealógicos y no saben, más allá de ellos, dónde localizar estos contenidos cuando las parroquias no se los proporcionan; por tanto, cayendo en el riesgo de ejecutar investigaciones genealógicas erróneas o incompletas, con un alto ruido documental que podría ser subsanado con un conocimiento más específico de los archivos que custodia la Iglesia.

\section{Metodología}

El estudio de la historia familiar se afronta en muchas ocasiones sin una formación específica en la materia. Cualquier persona puede, en algún momento de su vida, preocuparse por los orígenes de su familia y sus antepasados; algunos se quedarán en la mera curiosidad sin llegar a realizar ningún trabajo y otros acabarán desarrollando algún tipo de investigación de mayor o menor complejidad.

Los archiveros eclesiásticos dan fe de que en la actualidadun número elevado de sus usuarioscarecen de formación específica al respecto; nos referimos con ello tanto a aspectos archivísticos como de tipo genealógico. Sin embargo, 
debemos ser conscientes y así tenemos la obligación de transmitirlo que las cuestiones genealógicas son un tipo de trabajo que se sitúa dentro de una disciplina científica y eso conlleva la utilización de una metodología determinada; es decir, no deben ser entendidas estas cuestiones como un mero pasatiempo que entretenga a nuestros usuarios en el archivo. La puesta en práctica de un método nos permite conseguir unas conclusiones válidas en nuestras investigaciones, en las cuales existe un menor porcentaje de error que en otras que se desarrollen sin base metodológica. Por tanto, en la realización de un estudio genealógico deben tenerse en cuenta una serie de reglas, la utilización de las cuales, con un método predeterminado, nos permite incluir estos trabajos dentro del campo científico (Nuevo Método, 2014).

Una cuestión importante a nivel metodológico que debe comprometer a los archiveros eclesiásticos es transmitir a sus usuarios que la ejecución de un método conlleva una serie de principios o reglas que les van a facilitar ejecutar una correcta reconstrucción genealógica, a saber: (1) optar siempre por fuentes documentales frente a las de tipo oral; (2) dar prioridad absoluta a los testimonios oficiales sobre los relatos de tipo personal; (3) contrastar los datos a partir de los documentos; (4) saber que las fuentes cuyo autor están más cercanas en el tiempo y lugar a los hechos que se investigan serán prioritarias; (5) comprobar la veracidad de los documentos y la identidad de las personas que en ellos aparecen, pues uno de los fallos más comunes en nuestros usuarios es la confusión entre personas con un mismo nombre o incluso con los mismos nombres y apellidos, y ante esta situación nuestros usuarios deben cerciorarse de la identidad concreta de cada miembro de la familia en base a otros datos o fechas; y (6) tener presente que es muy aconsejable, especialmente en documentos antiguos, revisar el papel, las tinturas, la escritura y tipografía empleada, con el fin de ver que esos elementos concuerdan con la época en la que se sitúan sus búsquedas.

En resumen, la investigación genealógica es un tipo de estudio que precisa del conocimiento de muchas temáticas para conseguir unos resultados positivos; en definitiva precisa de un método. En principio, cualquier técnica o método de investigación puede ser dirigida a los estudios genealógicos pero, lo cierto es que hay uno que está especialmente ligado a ellos, por cuanto consiste básicamente en la reconstrucción de las relaciones familiares. Nosotros archiveros eclesiásticos debemos hacer todo lo posible para que nuestros usuarios conozcan dicho método y lo pongan en práctica en sus investigaciones.
En la investigación social, la antropología se ha destacado por desarrollar técnicas de recolección de datos y análisis conceptual conocidas en su conjunto como método genealógico (Jociles, 2006; Picó, 1996; Ruiz Pérez, 1994). Podemos definir el método genealógico como el procedimiento técnico por el cual un investigador efectúa una recolección de datos sobre los integrantes - tanto ascendientes como descendientes- de una o más familias y efectúa después el procesamiento y análisis de esa información (Murdock, 1994, p. 110). Como primera tarea para utilizar este método los usuarios deben recoger la información y registrarla de forma sistemática. Comenzamos con $X$ (personaje punto de partida) y empezamos a anotar los nombres y datos de cada una de las personas que considera sus parientes.

En las familias pueden existir varios tipos de relaciones (Davinson Pacheco, 2007, p. 169, 175): conyugal, representa la unión entre esposo y esposa; consanguinidad, relación de $X$ con sus padres, hermanos e hijos y parentesco ficticio o ritual. Para que las genealogías que realizan nuestros usuarios tengan un valor metodológico necesitan identificar cada una de las posiciones (madre, padre, hermanos, etc.). Además, el método genealógico nos permite adentrarnos en otros patrones como oficios, localizaciones, escolaridad, conductas, matrimonios, fecundidad, educación, enfermedades, etc. Es ahí cuando entran en valor otros archivos eclesiásticos, al margen de los parroquiales. Sirva de ejemplo, como posteriormente, los archivos de seminarios. Los alumnos que ingresaban en estos centros debían aportar un certificado médico y otro de conducta; en ellos podemos observar patrones de enfermedades y comportamientos de sumo interés para el trazado de estos estudios. Por lo tanto es muy valioso que los archiveros eclesiásticos transmitamos a nuestros usuarios que en el momento de recoger la información todo dato es importante y a priori válido; dado que evitarán por una parte el ruido documental y por otra la repetición de búsquedas ya efectuadas. Hasta el momento del análisis no sabremos realmente cuáles son los datos significativos y cuáles no lo son. Los datos que nuestros usuarios van recopilando en el archivo, tras la consulta de los documentos, pueden ir anotándose en unas tarjetas que nosotros, archiveros, facilitaremos en nuestros centros. Si creamos un modelo tipo, como el que hemos diseñado y que se inserta posteriormente, facilitaremos a los usuarios, especialmente a aquellos con menor formación en contenidos genealógicos, unos patrones de búsqueda que darán efectivos resultados porque evitarán que se dispersen en las consultas 
y se concentren en los datos que les van a ser realmente útiles en sus investigaciones.

\author{
Registro de datos genealógicos en archivos eclesiás- \\ ticos \\ No: \\ Relación con $\mathrm{x}$ : \\ Nombres: \\ Apellidos: \\ Datos personales: \\ Edad: \\ Sexo: \\ Otros: \\ Lugar de nacimiento: \\ Rural/Urbano \\ Movimientos espaciales: \\ Desde hacia \\ Datos médicos (enfermedades o tendencias): \\ Escolaridad: \\ Profesión u oficio: \\ Lugar de trabajo:
}

Tabla I. Ficha de información genealógica

Esta tarjeta que hemos confeccionado es un modelo mínimo que consideramos que puede ser de gran utilidad en el marco de los archivos eclesiásticos. Posteriormente, y dependiendo del interés específico de la investigación que los usuarios acometan, pueden incluirse más datos para ser consultados en archivos civiles: religión, afinidad política o sindical; cuestiones económicas, etc. Un buen comienzo para registrar toda la información que aparece en los documentos es llegar hasta cuatro generaciones, es decir: yo igual un nombre; mis padres igual dos nombres; abuelos igual a cuatro nombres; bisabuelos igual a ocho nombres. De ahí hacia atrás, la consulta se torna más compleja, y deberá ser por tanto objeto de una investigación más profunda. En resumen, los datos de las genealogías aportan al investigador los nombres y las relaciones existentes entre todos aquellos con los que va a trabajar durante su quehacer investigador, así como sobre los individuos que se encuentran ausentes. Por otro lado, el estudio de las relaciones de parentesco sólo puede hacerse mediante una comprensión adecuada del método genealógico.

\section{Archivos eclesiásticos y contenidos genealógicos}

Es obvio que de nada sirve conocer una metodología de trabajo y unas pautas de actuación, si desconocemos dónde podemos localizar los contenidos necesarios para nuestras investigaciones. En la información facilitada por los archiveros eclesiásticos extremeños hemos detectado que los usuarios que acuden a sus archivos en busca de contenidos genealógicos desconocen qué archivos dentro del marco de la Iglesia católica pueden facilitarles estos contenidos. A lo sumo identifican los registros parroquiales. $Y$ aún menor es el número de usuarios que sabe dentro de los cuadros de clasificación de los mencionados archivos dónde se sitúan estos contenidos. Por tanto, acometemos ahora este objetivo: exponer cuáles son los archivos eclesiásticos que contienen documentos válidos para la ejecución de perfiles genealógicos y dentro de los cuadros de clasificación de los mismos-qué secciones y series documentales son las que deben utilizar.

\subsection{Archivos parroquiales}

Como ya indicábamos, a partir de la celebración del Concilio de Trento en 1563, las parroquias quedaron obligadas a recoger en libros los datos de sus feligreses, especialmente los relativos a nacimientos, matrimonios y defunciones (Diego, 2000, p. 341). Por tanto, los registros parroquiales se convierten en la primera fuente de consulta para el trazado de genealogías. Los genealogistas deberán consular los Registros Sacramentales contenidos en los archivos parroquiales. Esta primera serie agrupa a su vez, en líneas generales, las series correspondientes a los registros de actas de cinco o seis de los siete sacramentos administrados por la Iglesia; excepto el del Orden sacerdotal, que aparecerá en archivos de obispados y de seminarios. Además pueden localizarse registros especiales, como registros de bautismos reservados, de bautismos de expósitos, de primeras comuniones o de defunciones en hospitales, etc.

Registro de bautismos. Esta serie contiene las inscripciones de actas de bautizos. Al nombre del bautizado, fecha del bautizo, nombre del padre y sacerdote oficiante, se añadieron poco a poco otras circunstancias y nombres, como lugar de nacimiento, legitimidad o no del bautizado, profesión del padre, nombre de la madre, nombre de los abuelos, nombre de los padrinos, las parroquias de donde son naturales, etc. Las partidas van numeradas y en los márgenes de las mismas, además del nombre del bautizado y sus dos apellidos, puede haber diversas anotaciones: niños mellizos, partos prematuros, cambio de párroco, confirmación o matrimonio posterior con referencia exacta en el registro correspondiente, etc. En los libros actuales, al margen se señala la fecha de confirmación, 
matrimonio $u$ orden sacerdotal, datos de sumo interés para las investigaciones genealógicas.

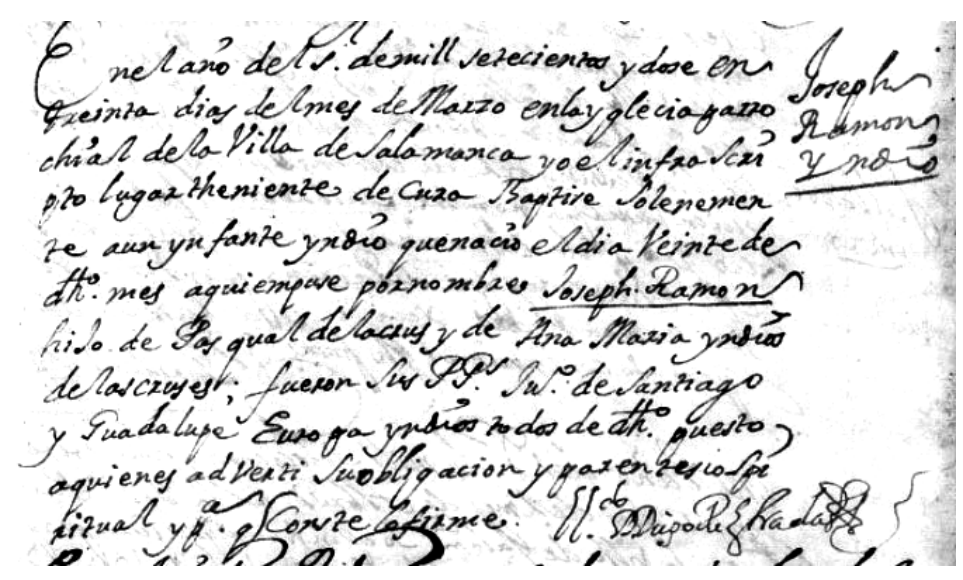

Figura 1. Registro libro de bautismo

Registro de matrimonios. En las actas registradas se suele indicar además del nombre de los contrayentes su estado de libertad y soltería, naturaleza y vecindad, la no existencia de impedimentos, la ejecución de las tres canónicas amonestaciones pertinentes, las dispensas eclesiásticas si las hubiese, el nombre y apellido de los padres y padrinos, el nombre del sacerdote oficiante, de los testigos, etc. Al margen suele inscribirse el nombre completo de ambos contrayentes. Además, como pueden observar en la imagen que se inserta de un expediente matrimonial actual, se pregunta a testigos, que aportan información adicional sobre los contrayentes, la cual puede relacionar a la persona analizada con otros parientes y amigos, ampliando el marco de trabajo genealógico.

Registro de comuniones. Aquí queremos comprender únicamente aquellos libros en que se hayan registrado actas o listas de personas que comulgaron o confesaron.

Registro de confirmaciones. No en todas las parroquias existía un libro en el que constaran relaciones nominales de confirmados; en muchos de los casos, se solían anotar en el libro de bautismos. Algunas anotaciones complementarias como nombre del obispo confirmante, padrinos, etc., figuraban casi siempre en el encabezamiento o final de las listas. En estos registros es muy interesante la figura del padrino porque en muchos casos se aporta la relación de parentesco o no, que mantiene con el confirmado, ampliando por tanto el marco de referencia genealógico.

Registro de defunciones. Esta serie corresponde a actas de fieles que han recibido el sacra- mento de la unción, extremaunción y sepultura eclesiástica.

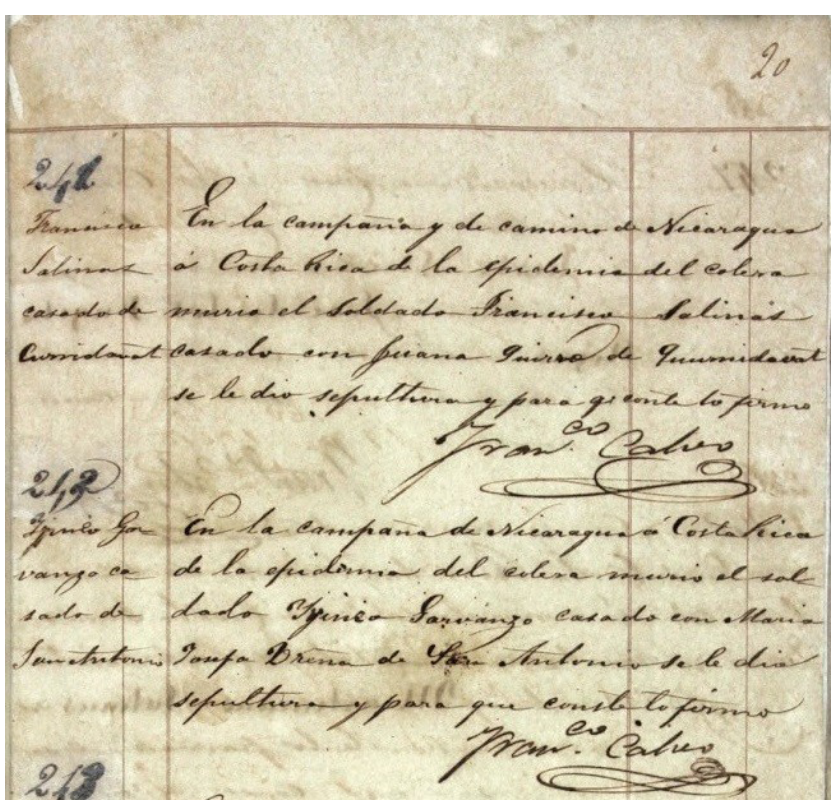

Figura 2. Registro libro de defunciones

En algunos lugares junto a los datos prosopográficos (fecha, nombre, apellidos, estado civil, edad y profesión del difunto, causa de la muerte, nombre del cónyuge del difunto, datos de los padres, etc.) se registraban también sus últimas voluntades. Al margen suele inscribirse el nombre completo del difunto.

\subsection{Archivos diocesanos}

Los archivos diocesanos son aquellos que custodian la documentación generada por el obispo y su curia en el desarrollo de sus múltiples actividades. Su datación se sitúa hacia el siglo XVI, muy estrechamente relacionada a las cláusulas emanadas del Concilio de Trento. Hasta dicho momento la documentación era ubicada junto al fondo catedralicio como consecuencia de que el obispo formaba parte del cabildo y debido a la inexistencia de los archivos diocesanos.

Los archivos diocesanos también son portadores de contenidos genealógicos. Lo son fundamentalmente de dos formas: en primer lugar, porque en muchas de las diócesis españolas - sirva de ejemplo la de Mérida-Badajoz de la que provenimos- se ha producido una concentración de los archivos parroquiales en diocesanos. Por tanto, por medio de los libros de bautismos, matrimonios y defunciones provenientes de las parroquias que concentran, son custodios de dichos contenidos genealógicos. Es importante que los usuarios conozcan en qué diócesis se ha realizado este proceso de concentración de ar- 
chivos, cada vez más habitual en el territorio español, dado que en aquellas en las que este procedimiento se haya desarrollado ya los usuarios podrán acceder a un mayor volumen de documentos con una mejor disponibilidad geográfica que si los contenidos que deben localizar están dispersos en diferentes emplazamientos. Además esta actuación tiene como finalidad muy clara la salvaguarda y disposición del patrimonio documental contenido en las parroquias.

En segundo lugar, los archivos diocesanos son portadores de contenidos de interés genealógico en sí mismos, es decir, los obispados generan una documentación muy útil para los genealogistas, especialmente en relación a varios procesos que dan lugar a diversas series documentales que debieran ser consultadas para el trazado de perfiles genealógicos al margen de las expuestas hasta el momento.

Padrones parroquiales. Esta serie se sitúa dentro de la sección administración del cuadro de clasificación de los archivos episcopales. Los padrones parroquiales pueden ser comparados con las listas censales en la vertiente civil dado que recogen datos de las personas (nombres, apellidos, ubicaciones, estudios, etc.) que pertenecen a una determinada parroquia, así como a su participación de los sacramentos. El interés de esta serie documental no viene relacionado con su parte eclesial, es decir, a la administración de los sacramentos, sino más bien por su aplicación sociológica, genealógica y demográfica dado que incluyen datos de sumo interés para investigaciones en dichas materias.

Anulaciones y dispensas matrimoniales. Se localizan estas series dentro de la sección de justicia, en la subsección matrimonios de los cuadros de clasificación de los archivos diocesanos. A su vez, ésta se constituye por las dos citadas series documentales: anulaciones y dispensas. Se trata de una documentación única, es decir, ningún otro archivo eclesiástico aporta información sobre estas materias. Por ello, estos contenidos adquieren un valor realmente importante. Debemos traer a colación estas series no tanto por los contenidos históricos que nos aportan, sino porque, dado que se tratade una documentación única, las personas que han participado en alguno de estos procesos sólo pueden encontrar en estos archivos el documento que atestigüe la validez del proceso, de marcado carácter probatorio. Desde el punto de vista de las genealogías estos contenidos adquieren un valor significativo cuando se trabaja en casos de consanguinidad o afinidad.

\subsection{Archivos de beneficencia}

Para comprender la función de las instituciones encargadas de la beneficencia en España nos será útil entender el sentido de la pobreza en la mentalidad cristiana de la Edad Media, para la cual el pobre era testimonio de la vida de Cristo. El cambio de mentalidad surge en el siglo XIV debido a la aparición de nuevos imperativos económicos y sociales y la existencia de un elevado número de centros gestionados por la Iglesia. Pero la variada actividad benéfica empieza a tocar fondo en el siglo XVII dado que las dotaciones se reducen y la pobreza comienza a ser un problema gestionado desde el Estado (Martínez Díez, 1997, p. 387-404). Las entidades benéficas incluían antaño instituciones tales como hospitales, hospicios, cementerios, asilos, etc. Todas ellas aportan interesantes contenidos para el estudio de perfiles genealógicos, dado que en sus registros aparecen datos sobre las personas que hicieron uso de sus servicios y son además fuentes complementarias para otras investigaciones de carácter sociológico, antropológico, demográfico, económico, etc.

La labor de asistencia al enfermo (hospitales) es por antonomasia la tarea que ha caracterizado a las entidades benéficas. Dentro de sus archivos son dos las series documentales que aportan datos a los genealogistas: los expedientes del personal contratado y muy especialmente los registros de enfermos, donde además de los datos personales de los pacientes (nombre, apellidos, edad, etc.) podemos acceder a contenidos sobre enfermedades que son de gran interés para completar los estudios genealógicos, teniendo en cuenta que en muchos casos estos datos son la base de investigaciones antropológicas de mayor amplitud. En relación a los cementerios son de utilidad los registros de defunciones (nombre, apellidos, fecha, causa de la muerte, etc.) y exhumaciones (nombre, apellidos, fecha, causa de la exhumación, etc.). Algo parecido sucede con los hospicios, donde el libro de asiento de niños recopila la información básica sobre adopciones, fallecimientos y solicitudes de ingresos, en las que se incluyen abundantes contenidos de carácter nominal.

\subsection{Archivos de órdenes religiosas}

Además de las órdenes mendicantes, existen otras órdenes religiosas que se denominan de vida activa porque nacen en tiempos más cercanos a los actuales y tienen un carisma renovador. Por regla general surgen después de la Reforma Protestante y del Concilio de Trento. Sus religiosos apenas se distinguen de los clérigos seculares o diocesanos. Mantienen vida en 
común, pero suprimen el coro, dedicando su tiempo a la vida apostólica o pastoral.

Dentro de las cuestiones que venimos desarrollando, nos interesan las órdenes religiosas que se han dedicado a la docencia, es decir, las que han estado al frente de colegios para la formación de niños y jóvenes. ¿Por qué este interés desde el punto de vista genealógico? Porque es en los archivos de estas instituciones donde podemos localizar una gran cantidad de contenidos de carácter genealógico; especialmente nos estamos refiriendo a sus registros de profesores y alumnos. En estos registros aparecen los datos personales, académicos y laborales de los alumnos y profesores que han formado parte de la institución docente a lo largo de los tiempos.

\subsection{Archivos de seminarios}

El nacimiento de una nueva institución orientada a la formación de los clérigos nos conduce directamente a la situación de la Iglesia católica en un periodo de confusión doctrinal provocada por las teorías de Lutero, Calvino y Zwinglio. La teología católica comenzaba a resquebrajarse, por lo que fue necesario un impulso a la formación sacerdotal. Así pues, los seminarios nacieron a raíz del Concilio de Trento como centros para atender la formación del clero (Rops, 1970, p. 104). Desde el punto de vista de las cuestiones genealógicas, los archivos de seminarios son grandes desconocidos; sin embargo contienen datos de gran interés para los genealogistas desde mediados del siglo XVI a nuestros días.

De las aulas de estos centros nacieron a la sociedad obispos, sacerdotes, maestros, gobernadores, políticos, alcaldes, músicos, médicos, literatos..., muchos de ellos de una talla intelectual inigualable. Otros muchos pasaron desapercibidos al no ocupar un puesto relevante en la sociedad aunque sí dejando huella de su paso en los archivos de estos centros. Es muy significativo reflejar que estos centros formativos fueron durante largos periodos de tiempo centros de educación punteros en las diferentes regiones donde se desarrollaron; sirva de ejemplo la ciudad de Badajoz, en la que su Seminario se convirtió en la primera universidad de Extremadura cuando no existía a nivel civil (Blanco Cotano, 1998; González Lozano, 2015).

El investigador que desee adentrarse en el estudio genealógico de alguno de los alumnos que estudiaron en los seminarios, encontrará en estos archivos una fuente fundamental que le ayudará a comprender su historia personal y familiar por medio de documentos. Es muy importante que los genealogistas conozcan que dentro de los cuadros de clasificación de los archivos de seminarios (Vivas Moreno, González Lozano y Pérez Ortiz, 2016) se localizan dos secciones (secretaría y órdenes sagradas) y varias series documentales que deben conocer, dado que aportan diversos contenidos de carácter genealógico que serán fundamentales para sus estudios.

Comencemos con la primera sección, secretaría. El sustento fundamental de investigaciones de tipo genealógico en archivos de seminarios se encuentra en la sección secretaría, subsección asuntos académicos, especialmente en las series: solicitudes, matrículas, informaciones, expedientes de conducta y listados de alumnos. Estos documentos son de sumo interés para los genealogistas dado que aportan datos relativos a la ascendencia del seminarista en primer y segundo grado, es decir, padres y abuelos. Los seminaristas, cuando ingresaban en el seminario, presentaban una solicitud al obispo y al rector en la que reflejaban su nombre completo, procedencia, los nombres de sus padres, ser hijo legítimo, sus localidades de origen, domicilio, profesión de sus progenitores, etc.

Junto con el anterior documento se incorporaba una copia de la partida de bautismo. Mediante esta documentación ahondamos en el entramado genealógico de las familias de los candidatos, en primer y segundo grado de consanguinidad; los registros de bautismo recogen tanto los nombres de sus padres, abuelos, como los de sus padrinos, su naturaleza, fecha de nacimiento, incluso el ministro oficiante. Un ejemplo es la partida de bautismo del sacerdote extremeño Tirso Lozano Rubio, utilizada recientemente para el desarrollo de su biografía (González Lozano; Pérez Ortiz, 2016).

Ya dentro de los seminarios los datos personales de los alumnos junto con los de sus ascendientes directos aparecen en los libros de matrículas, listados de alumnos, expedientes de conductas y becas donde se añaden además la condición de pobreza de la familia solicitante, conductas morales del candidato, etc. Estos contenidos servirán a los investigadores además de para el trazado de simples perfiles genealógicos para el desarrollo de completas biografías en las que se estudien otros elementos sociológicos, antropológicos, educativos, etc.

En cuanto a la segunda sección que contiene contenidos de tipo genealógico, órdenes sagradas, hacemos referencia a aquellos jóvenes que tras su estancia en el seminario deciden recibir el sacramento del Orden sacerdotal. Recordemos que esta documentación no se incluía en los archivos parroquiales como sucedía con el resto de sacramentos. Es una documentación 
muy interesante formada por la solicitud al obispo, partida bautismal, certificados de conducta y resoluciones. En algunos seminarios esta documentación es enviada a los respectivos obispados por lo que también podría ser localizada en los archivos diocesanos o episcopales dependiendo de cada diócesis.

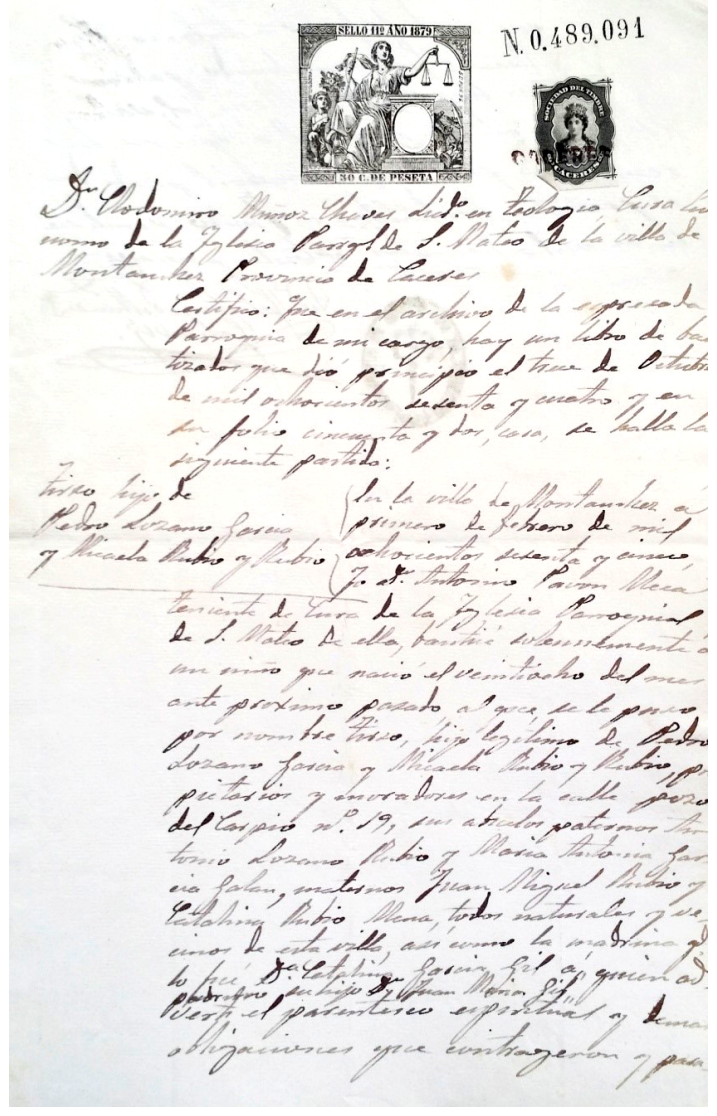

Figura 3. Partida de bautismo de un seminarista

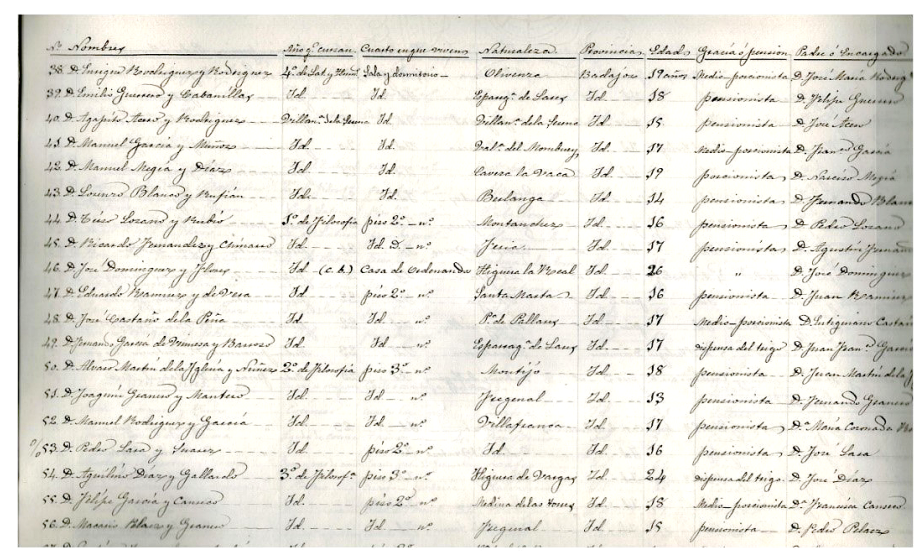

Figura 4. Listado de alumnos del Seminario San Atón de Badajoz

\section{Conclusiones}

Como han podido observar a lo largo de este cuarto epígrafe, los contenidos susceptibles de formar parte de investigaciones de tipo genealógico provenientes de los archivos de la Iglesia son muy variados apareciendo reflejados en un nutrido conjunto de archivos eclesiásticos. Somos conscientes que la utilización exclusiva de los registros parroquiales dará lugar a investigaciones genealógicas incompletas que podrían verse enriquecidas accediendo a los documentos contenidos en archivos de obispados, beneficencia, órdenes religiosas y de seminarios, y que se resumen en la Tabla II, en la página siguiente.

\begin{tabular}{|c|c|c|}
\hline Archivos & Secciones/subsec. & Series \\
\hline Parroquiales & $\begin{array}{l}\text { Registros } \\
\text { sacramentales }\end{array}$ & $\begin{array}{l}\text { Reg. bautismos } \\
\text { Reg. matrimonios } \\
\text { Reg. defunciones } \\
\text { Reg. comuniones } \\
\text { Reg. confirmaciones }\end{array}$ \\
\hline \multirow[t]{3}{*}{ Obispados } & $\begin{array}{l}\text { Registros } \\
\text { sacramentales } \\
\text { (concentración de } \\
\text { archivos) }\end{array}$ & $\begin{array}{l}\text { Reg. bautismos } \\
\text { Reg. matrimonios } \\
\text { Reg. defunciones } \\
\text { Reg. comuniones } \\
\text { Reg. confirmaciones }\end{array}$ \\
\hline & Justicia/matrimonios & $\begin{array}{l}\text { Anulaciones } \\
\text { Dispensas }\end{array}$ \\
\hline & Administración & Padrones \\
\hline \multirow[t]{3}{*}{ Beneficencia } & Hospitales & $\begin{array}{l}\text { Exp. personal } \\
\text { Registros de } \\
\text { enfermos }\end{array}$ \\
\hline & Cementerios & $\begin{array}{l}\text { Registro } \\
\text { defunciones }\end{array}$ \\
\hline & Hospicios & Asientos de niños \\
\hline $\begin{array}{l}\text { Órd. Vida } \\
\text { activa }\end{array}$ & $\begin{array}{l}\text { Docencia/alumnos/ } \\
\text { profesorado }\end{array}$ & Exp. Personales \\
\hline \multirow[t]{2}{*}{ Seminarios } & $\begin{array}{l}\text { Secretaría/ } \\
\text { Asuntos académicos }\end{array}$ & $\begin{array}{l}\text { Solicitudes } \\
\text { Matriculas } \\
\text { Informaciones } \\
\text { Exp. conductas } \\
\text { Becas } \\
\text { Listados }\end{array}$ \\
\hline & Órdenes sagradas & Exp. personales \\
\hline
\end{tabular}

Tabla II. Archivos eclesiásticos y contenidos genealógicos

Además, del estudio expuesto podemos extraer cuatro conclusiones.

En primer lugar, el boom genealógico que se está desarrollando en la actualidad obliga a los archiveros, muy especialmente a los eclesiásticos, a replantearse algunos de sus métodos de trabajo, así como a ofrecer a sus usuarios formación y herramientas que les permitan realizar 
consultas para la obtención de resultados satisfactorios.

En segundo lugar, el estudio de las relaciones de parentesco sólo puede hacerse mediante una comprensión adecuada del método genealógico, dado que es una herramienta de vital importancia, tanto para la recolección de información como para la representación y el análisis posterior de los contenidos genealógicos.

En tercer lugar, la base para la construcción de un buen perfil genealógico implica necesariamente, además de los datos obtenidos a través de entrevistas, los datos contenidos en los documentos de archivo, porque son el reflejo fiel de nuestro pasado. El método genealógico permitirá a los investigadores estudiar, más allá de los contenidos nominales, otros importantes patrones, tales como desplazamientos geográficos, escolaridad, afiliación política y sindical, patrones de matrimonio, enfermedades, educación, religión, etc.

Finalmente, los archivos eclesiásticos son vitales para el trazado de genealogías en nuestro país fundamentalmente debido a su antigüedad (s. XVI) y a su continuidad en el tiempo. No sólo los registros parroquiales contienen datos de utilidad para los estudios genealógicos. Como ya hemos visto, los usuarios deben acceder a otros archivos eclesiásticos tales como de obispados, de beneficencia, de órdenes religiosas y de seminarios, para completar sus investigaciones genealógicas.

\section{Referencias}

Alfaro de Prado, Antonio (2004). El Registro Civil de 18411870,30 años de provisionalidad. http://www.genealogia hispana.com/archivos/el-registro-civil-de-1841-1870.

Asociación de Genealogía Española. http://hispagen.es/ (2016-03-15)

Belmonte García, Adrián (2011). Archivos personales y familiares de la región de Murcia. // Tejuelo. 11 (2011) 5.

Berdún Nadal, Emilio (2008). Heráldica y genealogía. [s.I.]: E. Berdún, 2008.

Blanco Cotano, M. (1998). El Primer Centro Universitario de Extremadura. Historia Pedagógica del Seminario de San Atón. Cáceres: Universidad de Extremadura, 1998.

Bravo Lledó, Pilar (2004). Los archivos personales. Una manera de trabajar sus documentos. // Martín Abad, Julián (coord.). Seminario de archivos personales. Madrid: Biblioteca Nacional, 2004. 91-104.

Cadenas y Vicent, Vicente de (1978). Normas básicas para las investigaciones genealógicas. Madrid: CSIC, 1978.

Cuadernos de Genealogía http://cuadernos.hispagen.es/ index.php/cuadernos (2016-03-15)

Davinson Pacheco, Luis (2007). Una mirada al método genealógico y un ejemplo de su aplicación en un pueblo de Tlaxcala, México.// Familia y Diversidad en América Latina. Estudios de casos. Buenos Aires: Consejo Latinoamericano de Ciencias Sociales, 2007.
Diego, Natividad de (2000). Los archivos españoles de la Iglesia Católica. // Cuadernos de historia moderna. 25 (2000) 339-372.

Directorio de Genealogía Hispana http://www.genea logiahispana.com/directorio/(2016-03-15)

Espinosa Ramírez, Antonio Bernardo (1995). Los archivos personales: metodología para su planificación. // Ruíz Rodríguez, Antonio Ángel (coord.). Manual de archivística. Madrid: Síntesis, 1995. 261-ss.

Fluvià i Escorsa, Armand de (1995). A la recerca dels avantpassats: manual de genealogía. Barcelona: Curial, 1995.

Fugueras, R.; Mundet, Juan Ramón (2004). El árbol genealógico. La averiguación de nuestros antepasados... Madrid: Alianza Editorial, 2004.

Galiana Chacón, Juan P. (2004). De los archivos personales, sus características y su tratamiento técnico. // Martín Abad, Julián (coord.). Seminario de archivos personales. Madrid: Biblioteca Nacional, 2004. 17-28.

Gallego, Olga (1993). Manual de archivos familiares. Madrid: Anabad, 1993.

García Pérez, Ma Sandra (2009). Apuntes sobre los archivos parroquiales en España. // Biblios. 33-34 (2009) 1-11.

González Lozano, F. Historia pedagógica del Seminario Conciliar de San Atón. 1951-1962. Badajoz: Fundación Caja Badajoz, 2015.

González Lozano, F.; Pérez Ortiz, G. Tirso Lozano Rubio: un extremeño al servicio de la sociedad, al servicio de la Iglesia. Badajoz: Caja Badajoz, 2016. (En prensa).

Guía de Archivos. http://www.scrinia.org/uploads/guia/ guia_archivos.pdf (2016-03-15)

Guía Genealógica Española. http://www.genealogiaes.com/guia.html (2016-03-15)

Jociles, María Isabel (2006). Método genealógico e historias familiares... // Revista Venezolana de Sociología y Antropología, 47:16 (2006). 793-835.

Manual de Genealogía. http://www.genealogiahispana.com/ (2016-03-15)

Martínez Díez, G. (1997). Hospicios, casas de caridad y casas de misericordia. // Memoria Ecclesiae. 11 (1997) 387-404.

Murdock, George (1994). Guía para la clasificación de los datos culturales. México: UNAM, 1994.

Nuevo método práctico para genealogía (2014). Barcelona: Abueling, 2014.

Picó, Fernando (1996). La reconstitución genealógica: una herramienta para la historia social en Exegesis. Puerto Rico: Universidad, 1996.

Rops, Daniel (1970). Historia de la Iglesia. 7 vols. Madrid: Luis de Caralt, 1970.

Ruiz Pérez, Sonia (1994). El método genealógico. // Boletín de la Sociedad Puertorriqueña de Genealogía. 6:1-2 (1994).

Salazar y Acha, Jaime de (2006). Manual de genealogía española. Madrid: Hidalguía, 2006.

Segura Urra, Félix (2014). Fondos y colecciones personales y familiares en el Archivo Real y General de Navarra. // Príncipe de Viana. 75:260 (2014) 665-700.

Vivas Moreno, A.; González Lozano, F.; Pérez Ortiz, G. El Archivo del Seminario Metropolitano San Atón de Badajoz. Madrid: Marcial Pons, 2016. (En prensa).

Enviado: 2016-07-28. Segunda versión: 2017-03-21 Aceptado: 2017-05-09. 